\title{
Senile cataracts and the HLA system
}

\author{
J. GÁllvez Jr, ${ }^{1}$ E. PAREJA, ${ }^{2}$ M. G. MARCOS, ${ }^{1}$ M. J. BOLAÑOS, ${ }^{3}$ ANd F. GARRIDO \\ From 'Servicio de Oftalmología y ${ }^{2}$ Sección de Inmunología del Servicio de Análisis Clínicos de la Ciudad \\ Sanitaria 'Virgen de las Nieves' de Granada, ${ }^{3}$ Sección de Bioestadística de la Cátedra de Fisiología y Bioquímica \\ de la Facultad de Medicina de Granada, Spain
}

SUMmARY HLA A, B, and C typing was performed on a group of 309 southern Spanish people, namely, 207 controls and 102 patients who underwent a senile cataract extraction. Comparison of the results in the 2 groups (chi-square test) showed in the senile cataract group a significant increase in the association with HLA A9 $(p<0.01)$, HLA A blank $(p<0.005)$, HLA B5 $(p<0.005)$, HLA $B 13(p<0.03)$, and HLA B blank $(p<0.01)$ and a significant decrease in the association with HLA A2 (p<0.05), HLA Aw24 (p<0.001), HLA B27 (p<0.025), HLA Cw2 (p<0.001), and HLA Cw5 $(p<0 \cdot 01)$. The factors underlying these increased and decreased associations are conjectural.

The major histocompatibility system of man (the HLA system) consists of many closely linked genes on the short arm of chromosome 6 . Several loci can be distinguished. Some of them are responsible for graft rejection and are serologically defined (loci A, B, C, and DR), and another controls the mixed lymphocyte reaction (locus D). ${ }^{1}$

The association between the HLA system and several diseases has been reported by different authors. ${ }^{2}$ In ophthalmology it has been reported in the cases of glaucoma, ${ }^{3}$ anterior uveitis, ${ }^{4}$ Behçet's disease,$^{56}$ retinitis pigmentosa, ${ }^{7}$ and myasthenia gravis. $^{8}$

Senile cataracts and the HLA system have been studied recently ${ }^{9}$ without significant differences being found apart from a slight increase in the frequency of association with HLA A blank in relation to a control group.

\section{Material and methods}

A group of 309 southern Spanish people, 207 controls and 102 patients with senile cataracts, were studied. For an appropriate selection of the control group all those people suspected of suffering from a disease supposed to be related to the HLA system were rejected. The results were compared with those of other series in order to ascertain their significance value, the comparison being by the genetic identity

Correspondence to Dr José Gálvez Jr, Servicio de Oftalmologia, Ciudad Sanitaria de la Seguridad Social 'Virgen de las Nieves'. Granada, Spain. index. The criteria for selection of patients with senile cataracts were: age 45 or over, family history negative, and the recorded character of the primary cataract.

HLA typing was performed by the Sección de Inmunología, Servicio de Análisis Clínicos de la Ciudad Sanitaria 'Virgen de las Nieves' de Granada, Spain, by the standard lymphocyte microcytotoxic test.

\section{Results}

The results are shown in Table 1 . The chi-square test was used for a statistical analysis of the results. Values of $p$ were calculated from the distribution of the chisquare $^{10}$ and by Fisher's exact test ${ }^{11}$ (antigen B13). The significance level was predefined at $p=0 \cdot 05$.

Comparison between the 2 groups showed a significant increase in the association with HLA A9 $\left(\mathrm{p}<0.01 ; \chi^{2}=7.425\right)$, HLA A blank $\left(\mathrm{p}<0.005 ; \chi^{2}=\right.$ $8 \cdot 971)$, HLA B5 $\left(\mathrm{p}<0.005 ; \chi^{2}=10 \cdot 210\right)$, HLA B13 $\left(\mathrm{p}<0.03 ; \chi^{2}=4.794\right)$, and HLA B blank $\left(\mathrm{p}<0.01 ; \chi^{2}=\right.$ $7 \cdot 825)$ and a significant decrease in the association with HLA A2 $\left(p<0.05 ; \chi^{2}=4.071\right)$, HLA Aw24 $\left(\mathrm{p}<0.001 ; \chi^{2}=16.302\right)$, HLA B27 $\left(\mathrm{p}<0.025 ; \chi^{2}=\right.$ $5 \cdot 620)$, HLA Cw2 (p<0.001; $\left.\chi^{2}=17.962\right)$, and HLA Cw5 $\left(p<0.01 ; \chi^{2}=7 \cdot 587\right)$. The relative risks appear in Table 1.

\section{Discussion}

The clinical interest of the HLA-associated diseases in ophthalmology has been reduced to the above- 
Table 1 Phenotypic frequencies (PF) of the HLA antigens of loci $A, B$, and $C$ in senile cataracts patients

\begin{tabular}{|c|c|c|c|c|c|}
\hline \multirow{3}{*}{$\begin{array}{l}H L A \\
\text { antigen }\end{array}$} & \multicolumn{2}{|l|}{$P F(\%)$} & \multirow{3}{*}{$\begin{array}{l}\text { Relative } \\
\text { risk }\end{array}$} & \multirow[t]{3}{*}{$\chi^{2}$} & \multirow[t]{3}{*}{$p$} \\
\hline & Controls & Patients & & & \\
\hline & $(n=207)$ & $(n=102)$ & & & \\
\hline Al & $23 \cdot 18$ & $22 \cdot 54$ & 0.96 & $0 \cdot 016$ & \\
\hline A2 & $46 \cdot 37$ & $34 \cdot 31$ & $0 \cdot 60$ & $4 \cdot 071$ & $<0 \cdot 05$ \\
\hline A3 & $17 \cdot 39$ & $9 \cdot 80$ & 0.51 & $3 \cdot 104$ & \\
\hline A9 & $6 \cdot 76$ & $16 \cdot 66$ & $2 \cdot 75$ & $7 \cdot 425$ & $<0 \cdot 01$ \\
\hline A 10 & $8 \cdot 21$ & $8 \cdot 82$ & $1 \cdot 08$ & 0.033 & \\
\hline Al1 & $14 \cdot 97$ & $15 \cdot 68$ & $1 \cdot 05$ & $0 \cdot 027$ & \\
\hline Aw19 & $1 \cdot 44$ & 1.96 & $1 \cdot 36$ & $0 \cdot 112$ & \\
\hline Aw23 & 0.48 & 0.00 & $0 \cdot 0$ & - & \\
\hline Aw24 & $18 \cdot 35$ & 1.96 & $0 \cdot 08$ & $16 \cdot 302$ & $<0 \cdot 001$ \\
\hline A25 & $5 \cdot 31$ & $4 \cdot 90$ & $1 \cdot 07$ & 0.024 & \\
\hline A26 & 0.96 & $2 \cdot 94$ & $3 \cdot 12$ & 1.674 & \\
\hline A28 & $3 \cdot 86$ & $2 \cdot 94$ & 0.75 & $0 \cdot 170$ & \\
\hline A29 & 14.97 & $17 \cdot 64$ & $1 \cdot 21$ & $0 \cdot 365$ & \\
\hline Aw30 & $8 \cdot 69$ & $14 \cdot 70$ & $1 \cdot 81$ & $2 \cdot 588$ & \\
\hline Aw31 & 1.93 & 1.96 & $1 \cdot 01$ & $0 \cdot 0002$ & \\
\hline Aw33 & $4 \cdot 34$ & $5 \cdot 88$ & $1 \cdot 37$ & $0 \cdot 348$ & \\
\hline A blank & $21 \cdot 25$ & $37 \cdot 25$ & $2 \cdot 19$ & $8 \cdot 971$ & $<0 \cdot 005$ \\
\hline B5 & $10 \cdot 62$ & $24 \cdot 50$ & $2 \cdot 73$ & $10 \cdot 210$ & $<0.005$ \\
\hline B7 & $15 \cdot 94$ & $13 \cdot 72$ & $0 \cdot 83$ & $0 \cdot 260$ & \\
\hline B8 & $10 \cdot 14$ & $14 \cdot 70$ & 1.92 & $1 \cdot 381$ & \\
\hline B12 & $2 \cdot 89$ & 3.92 & $1 \cdot 37$ & $0 \cdot 228$ & \\
\hline B13 & $1 \cdot 44$ & $5 \cdot 88$ & $4 \cdot 27$ & $4 \cdot 749$ & $<0.03$ \\
\hline B14 & $15 \cdot 45$ & $9 \cdot 80$ & 0.59 & $1 \cdot 861$ & \\
\hline B15 & $8 \cdot 69$ & $7 \cdot 84$ & 0.89 & 0.064 & \\
\hline Bw16 & $3 \cdot 38$ & $7 \cdot 84$ & $2 \cdot 43$ & 2.945 & \\
\hline B17 & $4 \cdot 83$ & 1.96 & $0 \cdot 39$ & $1 \cdot 508$ & \\
\hline B18 & $15 \cdot 45$ & $13 \cdot 72$ & 0.87 & $0 \cdot 162$ & \\
\hline Bw21 & $8 \cdot 69$ & $6 \cdot 86$ & 0.77 & $0 \cdot 309$ & \\
\hline Bw22 & $5 \cdot 31$ & $2 \cdot 94$ & 0.54 & $0 \cdot 889$ & \\
\hline B27 & $9 \cdot 17$ & 1.96 & $0 \cdot 19$ & $5 \cdot 620$ & $<0.025$ \\
\hline Bw35 & $20 \cdot 77$ & $17 \cdot 64$ & $0 \cdot 81$ & 0.421 & \\
\hline B37 & 0.48 & 0.00 & $0 \cdot 0$ & - & \\
\hline Bw38 & 0.48 & $0 \cdot 00$ & $0 \cdot 0$ & - & \\
\hline B40 & $8 \cdot 21$ & $6 \cdot 86$ & $0 \cdot 82$ & $0 \cdot 174$ & \\
\hline Bw42 & 0.00 & 0.98 & 0.0 & - & \\
\hline Bw44 & $17 \cdot 05$ & $20 \cdot 58$ & $0 \cdot 69$ & $1 \cdot 526$ & \\
\hline Bw்45 & $1 \cdot 44$ & 1.96 & $1 \cdot 36$ & $0 \cdot 112$ & \\
\hline Bw47 & 0.97 & 0.00 & $0 \cdot 0$ & - & \\
\hline Bw48 & 0.48 & 0.00 & 0.0 & - & \\
\hline Bw49 & 0.48 & 0.98 & $2 \cdot 05$ & $0 \cdot 263$ & \\
\hline Bw50 & $5 \cdot 31$ & $4 \cdot 90$ & $0 \cdot 91$ & 0.024 & \\
\hline Bw51 & $6 \cdot 76$ & $0 \cdot 00$ & $0 \cdot 0$ & - & \\
\hline Bw52 & 0.96 & $0 \cdot 00$ & 0.0 & - & \\
\hline Bw62 & 0.00 & 0.98 & $0 \cdot 0$ & - & \\
\hline B blank & $13 \cdot 52$ & $26 \cdot 47$ & $2 \cdot 30$ & $7 \cdot 825$ & $<0 \cdot 01$ \\
\hline Cw2 & $31 \cdot 88$ & $9 \cdot 80$ & $0 \cdot 23$ & 17.962 & $<0.001$ \\
\hline Cw3 & $10 \cdot 44$ & $13 \cdot 72$ & $1 \cdot 36$ & 0.872 & \\
\hline Cw4 & $21 \cdot 25$ & $18 \cdot 62$ & $0 \cdot 84$ & $2 \cdot 291$ & \\
\hline Cw5 & $9 \cdot 17$ & 0.98 & 0.09 & $7 \cdot 587$ & $<0.01$ \\
\hline
\end{tabular}

mentioned conditions..$^{3-8}$ But the disorders of the lens and, above all, senile cataracts have been reported without conclusive results only once. ${ }^{9}$ In that study an investigation of the HLA system in 60 patients suffering from senile cataract did not prove that they were associated and showed only an increase in the relation with HLA A blank against a control group. This may imply that HLA A homozygotes are more susceptible to this disease.

It was therefore thought we could work in an almost unexplored field because of the high frequency of disturbances in the transparency of the lens and the difficulty of their treatment and prophylaxis (apart from symptomatic cataracts).

Although nuclear sclerosis of the lens is a physiological process, not everybody develops an actual opacity; neither nuclear senile cataracts nor cortical opacities are universal. It follows that there is a difference between people suffering from senile cataract and the rest of the population. Without underrating the role of the phenotypic factors, environmental or not, we cannot exclude the possibility of a genetic factor, at least causing a predisposition. That is why the comparative study of HLA antigens in healthy people and in patients with senile cataract from the same geographic area was performed.

Our results may suggest that the antigens whose frequencies are significantly increased (in patients with senile cataract) point to a predisposing factor, whereas the antigens whose frequencies are significantly decreased point to a resistance or protective factor.

It can be assumed that the relationship between HLA and senile cataract is not very strong, and we cannot rely too much on an apparent association with different antigens. Nevertheless, as happens in other HLA-related diseases, the presence or absence of a specific antigen serves only as a predisposing or protective factor, but never involves a determinant character. Ankylosing spondylitis is a clear example of how only a low percentage of people who are HLA B27 positive suffer from the disease, though more than $90 \%$ of the patients possess the HLA B27 antigen.

\section{References}

1 Bodmer WF. The HLA system: introduction. Br Med Bull 1978; 34: 213-6.

2 Dick HM. HLA and disease: introductory review. Br Med Bull 1978; 34: 271-4.

3 Ritch R, Podos SM, Henley W, Moss A, Southren AL, Fotino M. Lack of association of histocompatibility antigens with primary open-angle glaucoma. Arch Ophthalmol 1978; 96: 2204-6.

4 Ohno S, Kimura SJ, O'Connor GR, Char DH. HLA antigens and uveitis. Br J Ophthalmol 1977; 61: 62-4.

5 Ohno S, Sugiura S, Itakura K, Aizawa M. Further studies on HLA antigens in Behçet's disease. Jpn J Ophthalmol 1978; 22: 62-7.

6 Gálvez Torres-Puchol J, Gimenez-Padilla L-F, Sanchez Ortega S, Pareja Tello E. Enfermedad de Behçet: consideraciones clinicas e inmunologicas. Arch Soc Esp Oftal 1981; 41: 845-55.

7 Heckenlively JR, Bastek JV, Pearlman JT, Gladden J, Terasaki 
P. HLA typing in retinitis pigmentosa. BrJ Ophthalmol 1981; 65: 131-2.

8 Kaakinen A, Pirskanen R. Tiilikainen A. LD antigens associated with HL-A8 and myasthenia gravis. Tissue Antigens 1975; 6: 175-82.
9 Hida M. Kuwahara K. Cataract and HLA antigen. Nippon Ganka Gakkai Zasshi 1978; 82: 751-4.

10 Remington RD. Schork MA. Estadistica Biometrica y Sanitaria. Prentice internacional. 1978.

11 Gremy F. Salmon D. Bases Statistiques. Paris: Dunod. 1969. 